\title{
CHEMICAL SUPPLY CHAIN COORDINATION BASED ON TECHNOLOGY LEVEL AND LEAD-TIME CONSIDERATIONS
}

\author{
Atieh Fander, Saeed Yaghoubi* and Javad Asl-Najafi
}

\begin{abstract}
The production and transportation of chemicals is a risky process with high-cost operations for members of the supply chain, where some of the materials deteriorate over time and deal with valuereduction challenges. This paper studies a two-stage hazardous chemicals supply chain with a supplier and a manufacturer in a finite time horizon with a constant deterioration rate for both sides. To prevent potential hazards and improve product quality, the manufacturer invests in risk reduction and quality improvement technologies that can also attract more market demand. Owing to the importance of time in the storage and production of chemical products, this study focuses on a novel lead-time based discount contract to coordinate the channel members. The contract seeks to maximize the total profit of the chain by determining the optimal lead-time and manufacturer's technology level. By doing so, the supplier provides high-quality products and the manufacturer's unit supplying cost reduces and can buy more chemicals from the supplier. On the other hand, the supplier will have more time to supply the product and its initial cost will be reduced. As a result, the profit of both sides increases simultaneously. Some numerical examples are applied to examine the applicability of the proposed models. Finally, several sensitivity analyses on the main parameters are conducted to extract some in-depth managerial implications.
\end{abstract}

Mathematics Subject Classification. 91A11, 91A35.

Received August 11, 2020. Accepted February 28, 2021.

\section{INTRODUCTION}

With the rapid development of industries, chemical supply chains (CSC) deal with many challenges not only in procurement process but also during transport and storage. Due to the hazardous nature of chemicals, they can significantly harm people, property, and environment. In this regard, avoiding these hazards and mitigating risks are the main objectives in CSC. Since the hazardous chemicals contain flammable material, toxic gas, explosive, oxidant, etc., they must be transported and stored prudently according to legislation adopted by governments and authorities to keep safety in transport and storage processes. Furthermore, in order to reduce hazards, CSC members have to focus on investing in risk reduction technologies such as fire extinguishing technologies and toxic gas ventilation system. It is noteworthy to mention that the quality and quantity of chemicals decrease over time; hence, they are considered as deteriorating items. In addition, the effects of decaying on products become more important when chemicals are used to produce vital items.

Keywords. Chemicals supply chain coordination, deteriorating items, lead-time, discount contract, technology level.

School of Industrial Engineering, Iran University of Science and Technology, Tehran, Iran.

*Corresponding author: yaghoubi@iust.ac.ir 
Logistics is a critical issue in CSC, and therefore, any disruption in this area imposes a considerable cost on the supply chain. Logistics costs of CSC are significant and may be even up to $20 \%$ of the purchase cost [33]. A few occurred disasters in chemicals transportation played a crucial role in finding novel methods, tools, rules, and chemicals risk management. For example, the Bhopal disaster and the release of toxic materials in Seveso disaster are the worst instances that have happened up to now. To this end, many regulations are adopted in the European Union to control and mitigate disaster risks which are still named "Seveso" guidance [13-16].

Supply chains involve multiple activities and numerous members, whereas each of them undertakes a number of activities [3]. Thus, an effective cooperation among the members is needed to achieve optimal efficiency in supply chains. On the other hand, the main aim of each chain member is to optimize his/her own goal, and this self-centered focus on goals often leads to faint supply chain performance [8]. Additionally, in most cases the self-serving goals of players cause some profit conflicts among them. As a result, the members need to be coordinated by some incentive schemes (i.e., contracts) to achieve their optimal performance [28]. Given the importance of this issue, the concept of coordination in the CSC has not yet been fully addressed in the literature. In this regard, we decided to follow this issue in the current paper to fill the existing gap.

Supply chain coordination includes various mechanisms such as information technology, information sharing, joint decision-making, and contracts [2]. Noteworthy, contracts are the most common methods that have been applied in the coordination literature [27]. Due to the specific features of the existing problem, the routine contracts in the literature (i.e., revenue sharing, buyback, quantity discount, etc.) are not suitable for making channel coordination in this paper. It is necessary to mention that the quality of chemicals loses over the time; in this regard, delivery time has become a major element for CSC members. In general, during the implementation of the coordination mechanism, the manufacturer may decide on ordering time and the supplier is obliged to provide the order in an acceptable quality within the deadline, by contrast, sometimes there is a profit conflict between the two sides [31]. Accordingly, members should make a bilateral agreement on the allocation of profit and cost such that both sides achieve their satisfactory interests. As an effective effort to avoid decaying over the time, the lead-time reduction method may have an important role in CSC improvement. Due to the importance of lead-time in the chemicals industry, the lead-time based discount strategy can present an appropriate plan for coordinating CSC. When this contract are used to coordinate a hazardous chemicals supply chain in which both sides have a constant deterioration rate, the following main questions remain to be answered:

- Does the investment in quality and risk technologies affect demand growth?

- Can supply chain members accept this contract?

- How to increase lead-time will make more profit for both sides of the chain?

In this paper, we develop a two-echelon CSC consisting of a supplier and a manufacturer with deterministic demand affected by two endogenous variables including the technology level and the lead-time.

The main contributions of the current paper that differentiate it from the other similar investigations are stated below:

- Presenting a novel mathematical model for CSC coordination in the presence of deteriorating items.

- Analyzing the impact of lead-time in CSC due to the time-lag effect on product quality and decay on CSC.

- Implementing risk reduction technology to guarantee the safety of chemicals in the supply chain.

- Proposing a novel lead-time based discount contract as a tool for coordinating the CSC.

It should be noted that few articles in the literature have applied a lead-time based contract for making coordination. Nonetheless, many differences in the structure and application of our novel contract distinguish the extant work from the rest. One of the lead-time based models is presented by Huang et al. [31] and the other one is investigated by Heydari [26], where the chemical properties have not been considered at all. On the other hand, the demand function of chemical products in our model depends on lead-time of supplier and manufacturer's technology level, which is completely different from other studies in the literature. Moreover, none of the models in the literature has paid attention to risk reduction technology and we considered this issue in our model for the first time. 
The remainder of this paper is organized as follows. Section 2 reviews the relevant literature. In Section 3, the problem description is presented. Section 4 contains the mathematical models of the decentralized system. In Section 5, a novel lead-time based contract is suggested to coordinate the decentralized CSC. In Section 6, some sensitivity analysis is conducted to illustrate the applicability of the proposed models. Concluding remarks are presented in the final section.

\section{LiterATURE REVIEW}

As a whole, there are two main categories in the literature which have discussed about this paper's subject: Dangerous CSC and supply chain coordination with deteriorating items.

\subsection{Hazardous CSC}

Recently, due to irreparable disasters happened in transportation and storage of hazardous chemicals, many researchers have focused on risk reduction during CSC processes. Erkut and Verter [12] developed a risk model with the aim of evaluating transport risks and they also implemented different risk models on the U.S. road networks to achieve more insightful implications. Likewise, Zhang et al. [57] studied the risk of releasing toxic gases such as liquefied chlorine gas and liquid ammonia from hazardous chemicals in the air in case of leakage during the transportation process and estimated the relevant risk by using GIS technology. Considering the importance of routing issue in transportation risk assessment, Fabiano et al. [17] and Bubbico et al. [7] proposed a simple method to assess the risk of transporting hazardous materials. In this method, internal factors such as tunnel characteristics, bending radius, slope, and road and external factors such as transport trucks were considered. Wei et al. [48] and $\mathrm{Wu}$ et al. [50] analyzed the statistical date related to road accidents of nonexplosive dangerous chemicals. Additionally, Wei et al. [49] and Li et al. [38] developed mathematical models for hazardous chemicals transportation risk and evaluated some numerical analysis. Based on disasters data of the U.S. chemical industry from 1995 to 2000, Kleindorfer and Saad [35] proposed a model to evaluate and reduce CSC risks. In this regard, Zhang and Zhao [56] provided a model based on two dimensions of accident rates and simulated accident results to analyze the transportation risk of dangerous chemicals by using GIS technology. Gao et al. [19] demonstrated agent-based models to integrate chemical process information, process models, and assess the risk management decisions in CSC. None of the above-mentioned studies discussed the impact of transportation fleet capacity on risk. However, Guo and Verma [24] considered this issue in risk assessment for the first time and they supported flammable and explosive transportation management in Illinois, USA. Adhitya and Srinivasan [1] provided a simulating dynamic model to estimate CSC performance by considering customer behavior, sales strategies, and environmental issues. Laínez and Puigjaner [36] mentioned the risk prospective and perspective in the CSC in their review article. This review provides a wide range of CSC management focusing on classical approaches to make decisions based on the operations and integrating them into functional business domains by considering the dynamics of supply chain management. As regards to the importance of time in transportation risk, Li et al. [38] provided a dynamic risks model in CSC transportation, in which behavior of a time-dependent system was considered. Moreover, the flexibility of the correction model is reconciled to raise the practice in risk reduction. Due to the frequent disasters (explosions, fire, etc.) caused by hazardous chemicals in the warehouses, many researchers tried to find an efficient model to measure the safety level of the warehouses and identify risk factors. However, contrary to the mentioned articles, the risk of chemicals has not been discussed as a purely managerial factor in the current paper. The probability of an accident is a factor in the loss of products and the loss of customer demand. Managers' surveys have shown that by improving the quality of equipment and investing in risk reduction technologies, the incidence of accidents is significantly reduced, and therefore risk reduction and quality improvement have a direct impact on increased demand and subsequently profits. In this regard, in order to reduce and control the risks posed by transportation and storage of chemicals, we consider that the manufacturer invests in risk-reduction technologies. In this model, considering this factor as one of the main parameters of the model, its impact on other model parameters is carefully analyzed based on the obtained results. 


\subsection{Supply chain coordination with deteriorating items}

In the recent two decades, many articles have developed various coordination mechanisms to integrate the supply chain systems with deteriorating products. Due to the impact of deterioration on products, most studies have been discussed on inventory levels and ordering quantities. For example, Nahmias [43] first reviewed the ordering policies for deteriorating products and then illustrated the various types of inventory model. Yang and Wee [53] considered a two-stage supply chain with one supplier and a number of buyers. In this model, it is assumed that the rate of production and demand is constant and an optimal production policy for deteriorating items is proposed to coordinate members and minimize costs. In like manner, Lin et al. [39] presented a cooperative inventory strategy between supplier and buyer in two-stage supply chain system with deteriorating products within a specific time horizon. Ferguson and Koenigsberg [18] provided a two-period inventory model for deteriorating products where new products competed with the remaining products of the previous period and this effect is reflected in pricing and production in this model Yan et al. [52] suggested a centralized productiondistribution model for deteriorating products in a two-level supply chain, where the production batch size of supplier is limited to integer multiples of the quantity that should be delivered to the buyers. Similarly, Xiao and $\mathrm{Xu}$ [51] developed a Stackelberg game model for a supply chain with a supplier and a retailer for deteriorating items in order to analyze how to coordinate the system under vendor-managed inventory. They proposed a revenue-sharing contract to coordinate the supply chain. In this coordinating mechanism, the retailer has to pay a transfer price to supplier and supplier shared revenue with the retailer, which forced both members to share the revenues and costs. Rahdar and Nookabadi [44] investigated a two-level supply chain with one producer and various buyers for deteriorating products. The proposed coordination mechanism is based on the plan of buyer's delivery days and its relationship with manufacturer's production cycle. Investment in preservation technologies is one of the key issues that has not been addressed in the above-mentioned researches. In this direction, this topic is discussed by Zhang et al. [54] for the first time in the literature. They developed a model for a two-stage supply chain with one manufacturer and one retailer for deteriorating items with controllable deterioration rate and price-dependent demand, in which both members invested in preservation technology to mitigate deterioration. Recently, Bai et al. [5] investigated a two-echelon sustainable supply chain system for deteriorating products under carbon cap-and-trade policy with time-varying demand. Tiwari et al. [46] considered a two-echelon supply chain for deteriorating items with the limited capacity for the retailer's storage. Thus, the retailer stores the remaining inventory in an unlimited storage space. The proposed approach models price-product dependency, product demand, and retailer-supplier integration under four different policies (nonintegrated, integrated, supplier-led Stackelberg policy, and retailer-led Stackelberg policy) with the aim of maximizing the profits of both members. Then, Tiwari et al. [47] developed an integrated one-vendor one-buyer inventory model for deteriorating products considering carbon emission. In transport and storage activities, there is a possibility of carbon emissions while the amount of released carbon is sensitive to the vehicle type, the amount of consumed fuel, and the traveled distance. The purpose of their model is to provide a solution to decide on the frequency and quantity of deliverable products to reduce carbon emissions and minimize total costs. Huang et al. [32] studied a three-echelon Stackelberg game model for deteriorating food supply chain. Due to the complexity of the proposed mathematical model, an algorithm is used to obtain optimal values of pricing, inventory, and preservation decisions to maximize the profit of the members. Comparing the optimal decisions in forward and backward integration indicates that the vertical cooperation of members helps to improve the chain performance. Other relevant studies can also be found in $[4,9,10,22,23,29,55]$. Preventing deterioration is one of the significant challenges that supply chains deal with during the logistics processes. It is worth mentioning that little attention has been paid to the concept of lead-time discount up to now. This concept has mostly been addressed in management discussions. However, in most of the articles in the literature, the lead-time is not considered as one of the basic parameters of the model. He et al. [25] presented a production-inventory model for deteriorating products with several markets and various selling seasons, which emphasized on lead-time reduction to achieve the optimal replenishment schedule for raw materials and production plan for finished products. Huang et al. [31] considered a two-echelon supply chain with a single supplier and a single retailer 
with stochastic and stock-based demand in the developed model in which they focused on lead-time discount in order to coordinate supply chains with deteriorating items. Khanna et al. [34] proposed an integrated inventory model with one vendor and one buyer, where the production was done at the end of the vendor time period to meet the demand at the beginning of the buyer time period. As the manufacturing process was assumed to be imperfect it changed from an "in-control" condition to "out-of-control" condition at any random time and produced non-conforming products. Related discussions on lead-time discount coordination can also be found in $[30,37,42,45]$. Gautam and Khanna [20] proposed a sustainable supply chain with one vendor and one buyer, where the production system was imperfect. In order to meet sustainable goals, the model analyzed the carbon-emissions costs during the transportation process. Recently, Malekitabar et al. [41] developed a coordination mechanism for both ameliorating and deteriorating items called growing-mortal items in a two-echelon supply chain consisting of supplier and farmer. Moreover a revenue-sharing contract was proposed for deteriorating products in vendor-managed inventory for cold warehouses considering carbon emissions by Bai et al. [6]. Gautam et al. [21] considered a vendor-buyer green supply chain for analyzing defect management under two models. The integrated problem-solving approach was discussed in the first model and in the second model a Stackelberg game was developed. Daryanto et al. [11] developed a manufacturer-retailer inventory system for an imperfect manufacturing system with considering carbon emission cost for deteriorating products. Ma et al. [40] investigated in the effect of cap and trade regulation on the three-echelon cold supply chain where freshness level was the important factor for products.

In none of the above-mentioned articles, the impact and importance of time in CSC are addressed. Furthermore, due to the volatility nature of some chemicals, these materials are in the category of deteriorating items. To the best of our knowledge, this paper is the first study that analyzes the importance of time in CSC besides the implementation of a lead-time based contract, which follows the supply chain coordination goals.

In the current paper, a two-stage supply chain for chemicals is considered. Due to the volatility nature of some chemical materials, the specific properties of deteriorating items are assumed in this model. In addition, transportation and storage of these kinds of materials contain high risks and may lead to some disasters. In this study, unlike other similar investigations in the literature, the risks are not merely analyzed with managerial views. In other words, in this model, the manufacturer invests in risk reduction and quality improvement technologies, and the demand depends on two variables including technology level of the manufacturer and lead-time of the supplier. Due to the importance of time consideration in the CSCs, a lead-time based contract has been used to coordinate both CSC's members. That is while in none of the articles in the literature, the importance of delivery time and implementation of risk reduction technologies in CSC have fully investigated.

\section{Problem Description}

First, all of the notations applied in this paper are illustrated below. Then, a two-echelon CSC system with one supplier, one manufacturer, and a constant deterioration rate for both sides in a finite time horizon is considered. During the replenishment period $T$, in the first step, the manufacturer declares his order and his optimal lead-time for receiving the products to the supplier. In the second step, the supplier checks the registered orders and calculates his optimal lead-time to supply the products. In the third step, due to the longer time required by the supplier, the supplier will enter into negotiations with the manufacturer to persuade him to agree on a bigger lead-time. In the final step, the supplier begins to provide the products and must deliver them to the manufacturer at the end of the period. Due to the hazardous nature of chemicals and the high risk of transportation/maintenance of these products for the supplier, the manufacturer is obliged to pay the risk cost for per unit order. On the other hand, chemicals may cause disasters in the storage and production activities and this can result in irreparable environmental damages. Furthermore, with regard to the public attention on quality of products, environmental and safety issues, the manufacturer invests in risk reduction and quality improvement technologies to attract more demand from customers. It is noteworthy that the supplier needs more time to provide high-quality chemicals, which increases the demand and profitability of CSC. It is assumed that 


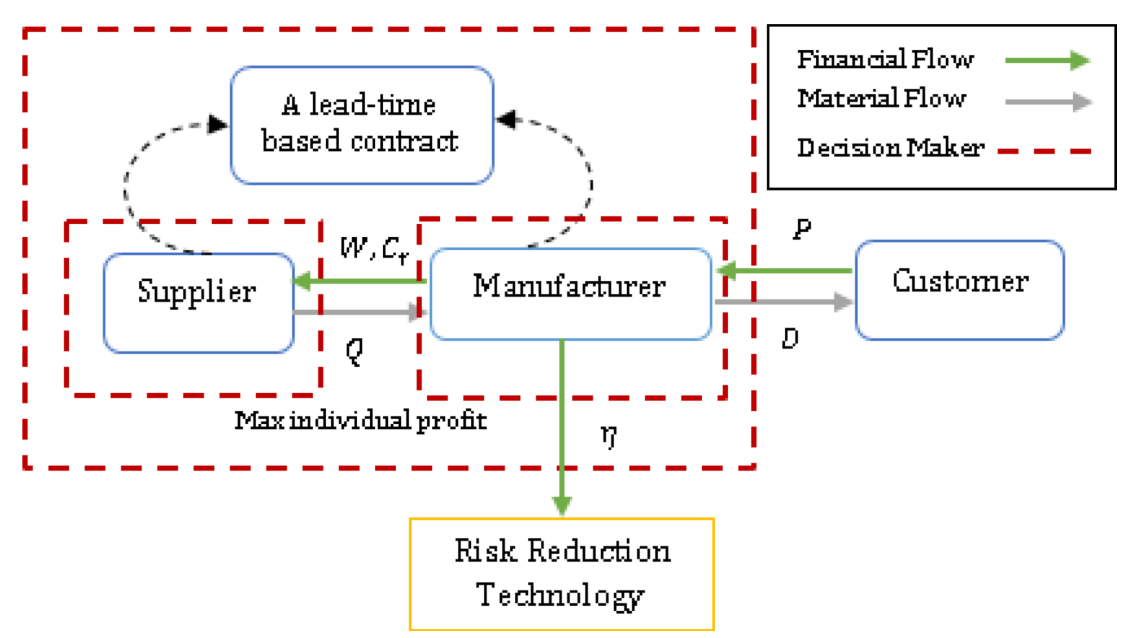

FigURE 1. The structure of the coordination mechanism.

the manufacturer faces a demand $D\left(l t_{m}, g\right)$, which is influenced by two major factors including lead-time and technology level. Figure 1 shows the structure of the coordination mechanism.

Providing more time to the supplier by the manufacturer raises demand, reduces initial costs for the supplier, and increases profits on both sides. On the other hand, it increases the ordering cost for manufacturer and has a harmful effect on his/her profit. To this end, the supplier and the manufacturer must agree on the lead-time in order to achieve the optimal profit for CSC.

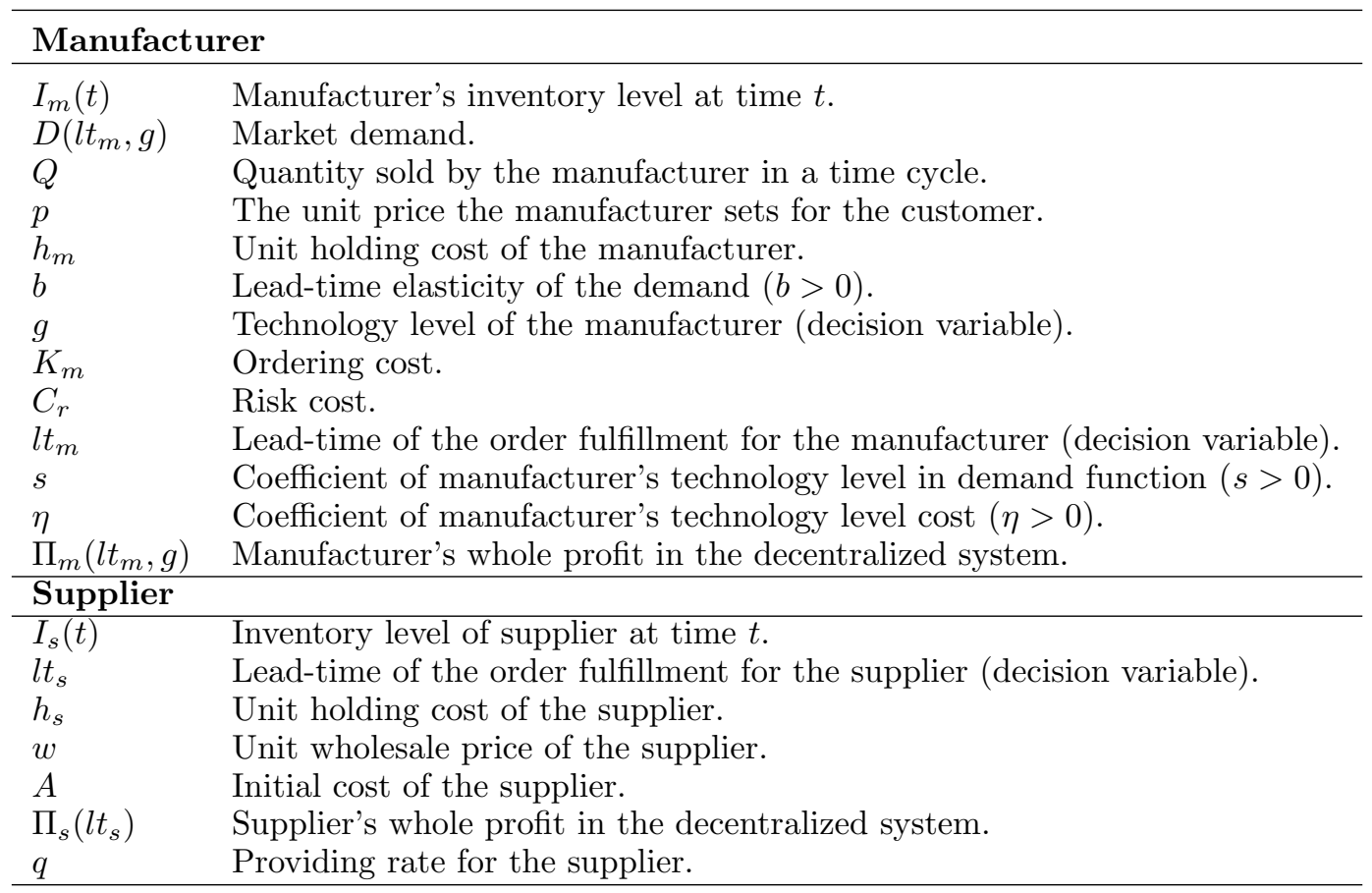




\begin{tabular}{ll}
\hline \multicolumn{2}{l}{ Supply chain } \\
\hline$\theta$ & Deterioration rate, $0 \leq \theta<1$. \\
$T$ & Fixed cycle length of replenishment, $T>0$. \\
$r$ & Discount factor. \\
$C_{d}$ & Unit deterioration cost. \\
$*$ & This is used to indicate the optimal value. \\
\hline
\end{tabular}

The main assumptions of this paper are stated as follows:

- Market demand is a function of manufacturer's technology level and lead-time. Let $D\left(l t_{m}, g\right)=a+b l t_{m}+s g$, where $a>0, b>0$, and $s>0$. Note that $a+b l t_{m}+s g>0$ is always satisfied.

- Due to the hazardous nature of chemicals and the high risk of transportation/maintenance of these products for the supplier, the manufacturer is obliged to pay the risks cost for per unit order. This type of cost functions have been inspired from several companies [58,59].

- Since both channel members are incapacitated, none of the supplier and manufacturer faces shortage.

- The setup time and cost are not considered for the supplier [5].

- The optimal lead-time for manufacturer is shorter than supplier's optimal [31].

- Quadratic function is assumed to formulate the technology investment cost for the manufacturer. This type of cost functions have been used by several articles in the literature (i.e. $[4,5,58])$.

\section{Mathematical modeling}

According to the problem descriptions, the behavior of the inventory system for both CSC members can be examined as follows. The manufacturer orders $Q$ from the supplier at time $T-l t$ and receives $Q$ at the end of period $T$. Manufacturer's inventory constantly decreases and reaches to zero at time $T$ because of demand and deterioration effects. On the other hand, supplier's inventory increases up to $Q$ at time $T$ because of the delivery of chemicals to the manufacturer. In this model, both sides of the supply chain decide on the lead-time according to their own interests. Although the final decision maker for lead-time is the manufacturer.

\subsection{Centralized system}

In this case, there is no centralized model between supplier and manufacturer, both members worry about their economic and their goal is to reach the maximum profit level for themselves. Since in this model, the lead-time is a decision variable for both sides, and both seek to optimize their own profit, so with respect to this joint decision variable in both sides, there is no integrated model in this case.

\subsection{Manufacturer's profit}

In this section, the manufacturer seeks to increase his/her own profit. The manufacturer faces a demand, which varies with technology level and lead-time. Indeed, as technology level $(g)$ and lead-time $(l t)$ increase, demand increases; likewise, increasing the demand value leads to an increase in manufacturer's profit. By contrast, as the lead-time increases, the ordering set up the cost of the manufacturer increases in a quadratic function with lead-time. Part of the setup ordering cost includes administrative costs, which may be subject to cancellation due to the inability of the predictor in estimating the exact delivery time. In essence, the event of a prolongation in delivery period can increase the administrative and setup ordering costs. This increase in costs is nonlinear, due to the fact that the financial losses of canceled orders will increase over a longer delivery period, costs are increased in nonlinear terms with the lead-time increases. Given the nature of the administrative costs and the connection with the lead-time, it is calculated as a quadratic equation. As a result, the ordering set up costs are given as $K_{m}=K_{0}+\gamma l t^{2}$, in which $K_{0}$ is the batch ordering setup cost and $\gamma>0$ is constant. In addition, the manufacturer invests in risk reduction and quality improvement technologies to attract more demand. As the technology level increases, its investment costs increase due to the complexity of installing and training employees in a non-linear way, which is why the cost function is considered as $-\frac{\eta g^{2}}{2}$. 


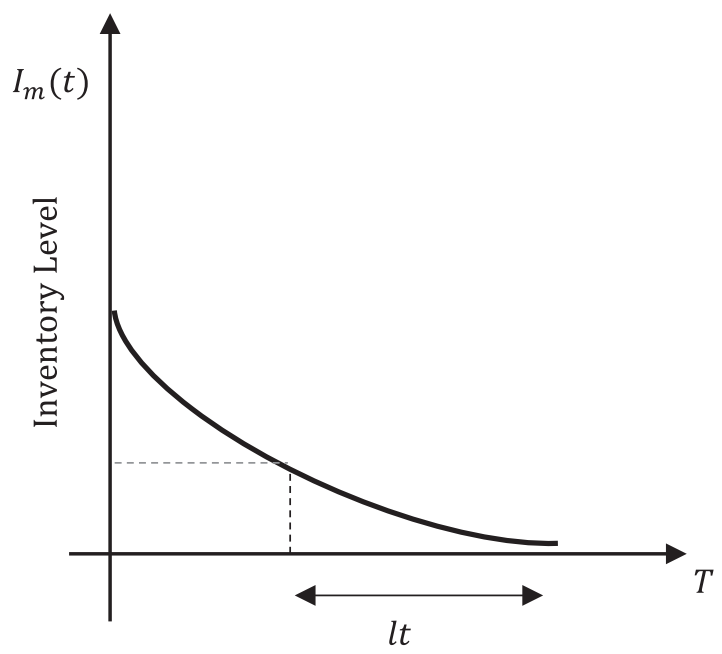

FiguRE 2. Manufacturer's inventory level.

Moreover, demand and products' deterioration rate occur a gradual reduction in the inventory level of manufacturer over the time. Figure 2 shows the inventory level $I_{m}(t)$ over the replenishment period for the manufacturer. The instantaneous inventory level is given by:

$$
\begin{array}{ll}
\frac{\mathrm{d} I_{m}(t)}{\mathrm{d} t}=-D\left(l t_{m}, g\right)-\theta I_{m}(t) & 0 \leq t \leq T \\
\frac{\mathrm{d} I_{m}(t)}{\mathrm{d} t}=-\left(a+b l t_{m}+s g\right)-\theta I_{m}(t) & 0 \leq t \leq T .
\end{array}
$$

Note that $I_{m}(T)=0$.

By solving equation (4.2), the manufacturer's inventory level at time $t$ is given by

$$
I_{m}(t)=\frac{\left(a+b l t_{m}+s g\right)}{\theta}\left[e^{\theta(T-t)}-1\right] .
$$

Theorem 4.1. The quantity of product sold by the manufacturer is as follows

$$
Q-\theta I_{m}=T\left(a+b l t_{m}+s g\right) .
$$

Proof. Please see Appendix A.

The total profit generated by the manufacturer is as follows:

$$
\Pi_{m}\left(l t_{m}, g\right)=p\left(Q-\left(\theta I_{m}\right)\right)-W Q-\left(h_{m}+\theta C d\right) I_{m}-\left(K_{0}+\gamma l t_{m}^{2}\right)-C_{r} Q-\frac{\eta g^{2}}{2} .
$$

In equation (4.5), the first term indicates the sales revenue of CSC. The second term states the supplying cost. The third term refers to the inventory holding cost and deterioration cost. The fourth term is ordering setup cost. The fifth term concerns to risks cost and the last term shows technology investment cost.

Theorem 4.2. The manufacturer's profit function is concave in $l t_{m}$ and $g$. Thus, the optimal and exclusive $\left(l t_{m}, g\right)$ can be obtained to maximize the manufacturer's expected profit. The optimal lead-time and technology 


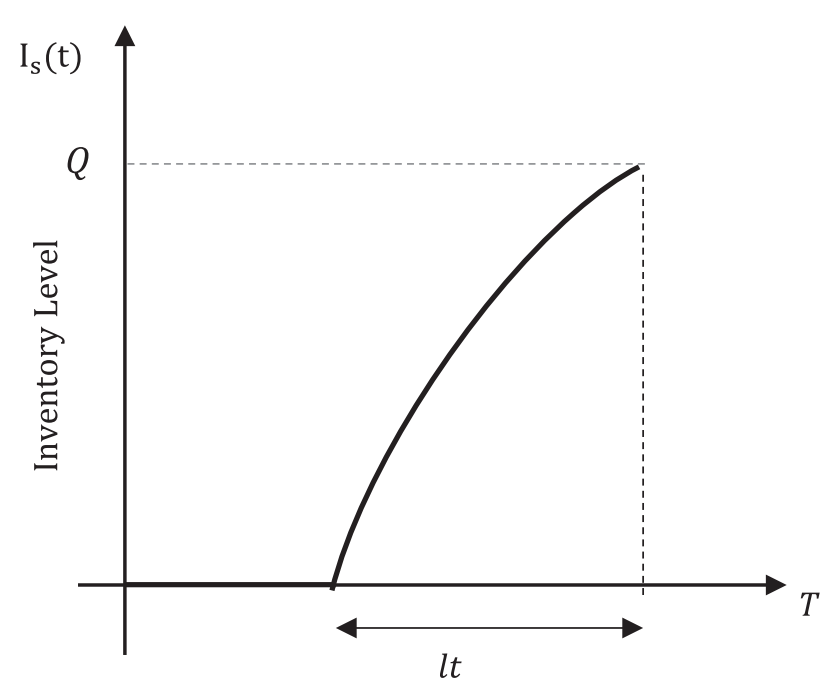

FigURE 3. Supplier's inventory level.

level are as follows, respectively.

$$
\begin{aligned}
l t_{m}^{*} & =-\frac{b\left(-C_{r} \theta+C_{r} e^{\theta T} \theta-h_{m}+e^{\theta T} h_{m}-\theta C_{d}+e^{\theta T} \theta C_{d}-\theta h_{m} T-\theta^{2} C_{d} T-\theta^{2} p T-\theta w+e^{\theta T} \theta w\right)}{2 \gamma \theta^{2}} \\
g^{*} & =-\frac{s\left(-C_{r} \theta+C_{r} e^{\theta T} \theta-h_{m}+e^{\theta T} h_{m}-\theta C_{d}+e^{\theta T} \theta C_{d}-\theta h_{m} T-\theta^{2} C_{d} T-\theta^{2} p T-\theta w+e^{\theta T} \theta w\right)}{\theta^{2} \eta} .
\end{aligned}
$$

Proof. Please see Appendix B.

\subsection{Supplier's profit}

The supplier starts supplying the products with a rate of $q$ per day after receiving orders from the manufacturer. The supplier has more time to supply the demand if the manufacturer declares the order earlier. Thus, it can provide products with lower initial cost and higher quality. Regarding that, the supplier's sales profit will go up with the initial cost reduction, which is denoted as $A=A_{0}-\varphi l t$, where $A_{0}$ is the base rate if the retailer places the order at the end of the period, and $\varphi>0$ is a constant value indicates that the unit production cost proportion decreases with lead-time. Because the supplier starts supplying the product after receiving the order, the inventory is zero before this stage. Therefore, as can be seen in Figure 3, the inventory level is given by $I_{s}(t)=0$ for $0 \leq t \leq T-l t_{s}$. Furthermore, the supplier's inventory increases during $T-l t_{s} \leq t \leq T$; on the other hand, it declines with deterioration rate. Notice that:

$$
\begin{aligned}
\frac{\mathrm{d} I_{s}(t)}{\mathrm{d} t} & =q-\theta I_{s}(t) T-l t_{s} \leq t \leq T \\
I_{s}(t) & =\frac{q}{\theta}\left[1-e^{\theta\left(\left(T-l t_{s}\right)-t\right)}\right] .
\end{aligned}
$$

With $I_{s}\left(T-l t_{s}\right)=0, I_{s}(T)=Q$.

Theorem 4.3. The supplier has an optimal supplying rate as

$$
q=\frac{\theta Q}{1-e^{-\theta l t_{s}}} .
$$




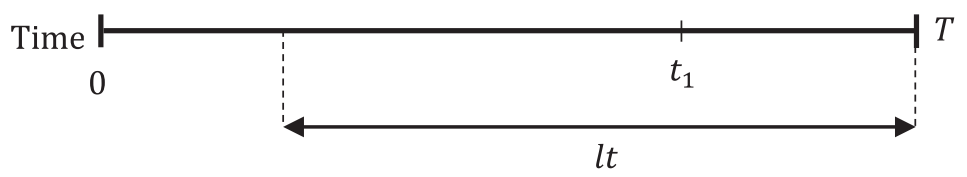

Figure 4. The possible lead-time for coordination.

Proof. Please see Appendix C.

The total profit generated by the manufacturer is presented as follows:

$$
\Pi_{s}\left(l t_{s}\right)=w Q-\left(A_{0}-\varphi l t_{s}\right) q l t_{s}-\left(h_{s}+\theta C d\right) I_{s}+C_{r} Q .
$$

In equation (4.11), the first term demonstrates the sales revenue of CSC. The second term indicates the supplying cost. The third term shows the aggregate costs of inventory and products deterioration and finally the last term refers to the risk revenue.

\section{LEAD-TIME BASED DISCOUNT COORDINATION}

As previously mentioned, the optimal lead-time of manufacturer is shorter than the optimal lead-time of supplier $\left(l t_{s}>l t_{m}\right)$. In this regard, the supplier is looking for a way to induce the manufacturer to adopt an extended lead-time. An earlier order increases the supplier's profit and may reduce the manufacturer's profit, so the supplier must offer the manufacturer a lead-time discount to compensate his/her lost profit. By doing so, both parties benefit from the suggested incentive mechanism and get a satisfying profit.

However, the supplier has to offer the manufacturer a lead-time discount, which does not harm his/her own profit. Therefore, an upper limit for discount is considered as follows:

$$
d_{\max }=\left[\Pi_{s}\left(l t_{s}\right)-\Pi_{m}\left(l t_{m}, g\right)\right] / \Pi_{s}\left(l t_{s}\right) .
$$

Accordingly, the ratio of extra profit $\left(d_{\max }\right)$ is obtained by substituting the supplier's optimal lead-time instead of the manufacturer's optimal lead-time in supplier's profit function. On the other hand, as shown in Figure 4, due to the preparation for provision, it is assumed that the supplier will not accept any demand after $t_{1}$ $\left(t_{1}<T\right)$. Therefore, the supplier proposes a discount plan based on $r=\left(\frac{t_{1}-\left(T-l t_{m}\right)}{t_{1}}\right)$ to the manufacturer, where $r<d_{\max }$, which gives the manufacturer a higher discount if he declares his order earlier. The parameter $r$ is added to the model as a constant discount factor based on the lead-time which is calculated before the contract by the manufacturer. Therefore, the supplier, based on the pre-contract optimal lead-time of the manufacturer, gives him a discount on the supplying cost and, in return the manufacturer based on the profits, should consider the longer lead-time for the supplier. Thus, the manufacturer's supplying cost reduces to $W(1-r)$ and the supplier's initial costs decrease as $\left(A_{0}-\varphi l t_{s}\right)$.

Regarding the above-mentioned statements, the members' profit functions are changed as follows:

$$
\begin{aligned}
\Pi_{m}\left(l t_{m}, g\right) & =P\left(Q-\left(\theta I_{m}\right)\right)-W(1-r) Q-\left(h_{m}+\theta C_{d}\right) I_{m}-\left(K_{0}+\gamma l t_{m}^{2}\right)-C_{r} Q-\frac{\eta g^{2}}{2} \\
\Pi_{s}\left(l t_{s}\right) & =w(1-r) Q-\left(A_{0}-\varphi l t_{s}\right) q l t_{s}-\left(h_{s}+\theta C d\right) I_{s}+C_{r} Q .
\end{aligned}
$$

After considering the discount parameter, the optimal variables are calculated as follows.

$$
\begin{aligned}
l t_{m}^{*} & =-\frac{b\left(-C_{r} \theta+C_{r} e^{\theta T} \theta-h_{m}+e^{\theta T} h_{m}-\theta C_{d}+e^{\theta T} \theta C_{d}-\theta h_{m} T-\theta^{2} C_{d} T-\theta^{2} p T-\theta r w+e^{\theta T} \theta r w\right)}{2 \gamma \theta^{2}} \\
g^{*} & =-\frac{s\left(-C_{r} \theta+C_{r} e^{\theta T} \theta-h_{m}+e^{\theta T} h_{m}-\theta C_{d}+e^{\theta T} \theta C_{d}-\theta h_{m} T-\theta^{2} C_{d} T-\theta^{2} p T-\theta r w+e^{\theta T} \theta r w\right)}{\theta^{2} \eta} .
\end{aligned}
$$


TABLE 1. Parameter values for the numerical experiments.

\begin{tabular}{llllllllll}
\hline \hline No & $b$ & $s$ & $\theta$ & $\eta$ & $\gamma$ & $\varphi$ & $h_{m}$ & $h_{s}$ & $C_{r}$ \\
\hline 1 & 0.50 & 0.6 & 0.080 & 10 & 7.0 & 0.90 & 0.75 & 0.5 & 4.0 \\
2 & 0.40 & 0.6 & 0.082 & 8 & 7.5 & 0.90 & 0.40 & 0.6 & 4.5 \\
3 & 0.45 & 0.5 & 0.082 & 9 & 7.5 & 0.85 & 0.40 & 0.5 & 3.8 \\
4 & 0.60 & 0.7 & 0.087 & 7 & 8.0 & 0.80 & 0.50 & 0.5 & 3.0 \\
5 & 0.20 & 0.4 & 0.087 & 7 & 5.0 & 0.95 & 0.30 & 0.3 & 2.0 \\
\hline
\end{tabular}

After coordination, the manufacturer may wish to make an earlier order to increase his demand and profit through lead-time based discount contract. By doing so, the manufacturer's profit increases and so he/she can invest more in risk reduction and quality improvement technologies. Thereby, customer satisfaction increases and also more demand attraction can be happened. On the other hand, by declaring the order earlier by the manufacturer, the supplier will have enough time to supply the products with an acceptable quality besides gaining a satisfying profit for himself. However, the manufacturer has the privilege to decide on the best ordering time and lead-time $\left(l t_{m}\right)$, while the supplier does not have enough power to deal with this decision. The supplier calculates his best lead-time $\left(l t_{s}\right)$ and by offering a lead-time based discount contract to the manufacturer, he tries to encourage the manufacturer to bring his decision about lead-time $\left(l t_{m}\right)$ closer to supplier's optimal lead-time $\left(l t_{s}\right)$. The difference between before and after coordination is that the manufacturer will announce his order earlier in order to use of discount benefits and subsequently the profits of both members increase. Thus, the total profits of CSC before and after coordination are as follows:

$$
\begin{aligned}
& \Pi_{T}=\Pi_{m}\left(l t_{m}, g\right)+\Pi_{s}\left(l t_{m}\right) \\
& \Pi_{T}^{*}=\Pi_{m}\left(l t_{m}^{*}, g\right)+\Pi_{s}\left(l t_{m}^{*}\right) .
\end{aligned}
$$

\section{NumericAl EVALUATION}

\subsection{Numerical examples}

In this section, numerical examples are devised to demonstrate theoretical results of lead-time coordination of CSC. The supplier has a replenishment period $T=20$ weeks and the manufacturer can place his order during this period. After investigating several periods, the supplier concludes that the worst time of order from the manufacturer is at $t_{1}$ and after this time, no order will be accepted. To conduct numerical evaluations, some of the parameters are assumed to be constant in all experiments as $a=150, t_{1}=17, K_{0}=5, A_{0}=10, W=30$, $P=105, C_{d}=1$, and $q=5$. The rest of parameter values for all five examples are given in Table 1 .

In Example \#1, in the decentralized model, when the first principal minor is negative $-2 \gamma=-14<0$ and the second principal minor is positive $2 \gamma \eta=140>0$, the optimal order of the manufacturer is placed at 15.9 weeks and the optimal technology level of the manufacturer is 6.88 . The profits for the manufacturer and the supplier in the decentralized model are $\Pi_{m}=17570.3$ and $\Pi_{s}=195980$ thousand dollars. After the implementation of coordination plan, the optimal order of the manufacturer is placed at 12.48 weeks and the optimal technology level of the manufacturer is 12.64. The profits of the manufacturer and the supplier after coordination increase to $\Pi_{m}=32800.1$ and $\Pi_{s}=203360$ thousand dollars. The results of the model indicate that after the coordination, the manufacturer is willing to give the supplier more time to provide the products and also increase his technology level. Tables 1 and 2 summarize the parameter values related to five presented numerical examples. 
TABLE 2. The results of the numerical examples before/after coordination plan.

\begin{tabular}{|c|c|c|c|c|c|}
\hline No. & $\begin{array}{l}\text { Before/After } \\
\text { coordination }\end{array}$ & $\begin{array}{l}\text { Supplier's } \\
\text { profit }\end{array}$ & $\begin{array}{l}\text { Manufacturer's } \\
\text { profit }\end{array}$ & Lead-time & $\begin{array}{l}\text { Manufacturer's } \\
\text { technology } \\
\text { level }\end{array}$ \\
\hline \multirow[t]{2}{*}{1} & Before & 195598 & 17570.3 & 4.1 & 6.88 \\
\hline & After & 203360 & 32800.1 & 7.52 & 12.64 \\
\hline \multirow[t]{2}{*}{2} & Before & 208480 & 26537.4 & 4.57 & 12.86 \\
\hline & After & 215044 & 49532.1 & 8.32 & 23.41 \\
\hline \multirow[t]{2}{*}{3} & Before & 207388 & 31923.5 & 6.209 & 11.498 \\
\hline & After & 237328 & 79116.5 & 14.817 & 27.439 \\
\hline \multirow[t]{2}{*}{4} & Before & 200984 & 13695.2 & 3.333 & 8.890 \\
\hline & After & 203658 & 18772.1 & 4.526 & 12.069 \\
\hline \multirow[t]{2}{*}{5} & Before & 202931 & 33806.1 & 4.420 & 12.630 \\
\hline & After & 204650 & 55560.2 & 7.127 & 20.365 \\
\hline
\end{tabular}

\subsection{Sensitivity analysis}

Some parameters have significant impacts on the performance of CSC and the results of coordination scheme. First, the impact of $\theta, \gamma$ and $\varphi$ on the CSC profit is analyzed and the results are shown in Figure 5. As can be seen in Figure 5, $\theta$ and $\gamma$ have a negative effect on the total profit of CSC while $\varphi$ has a positive effect, and by increasing this parameter, the CSC profit increases. As deterioration rate $\theta$ increases, corrupted products will increase during period $T$, and with this increase, the CSC's profit declines as more and more of the products are discarded. Furthermore, by increasing $\gamma$, the administrative and setup ordering costs for the manufacturer increases, as a result, the manufacturer's profit decreases and subsequently the CSC's profit declines. To overcome this problem, coefficient $\gamma$ must be set at an acceptable level from the manufacturer side. Contrary to two previous parameters, $\varphi$ has a direct relation with CSC's profit. By increasing the discount factor per unit lead-time on the supplier's initial costs, the supplier's profit increases which results in increasing the profit of CSC.

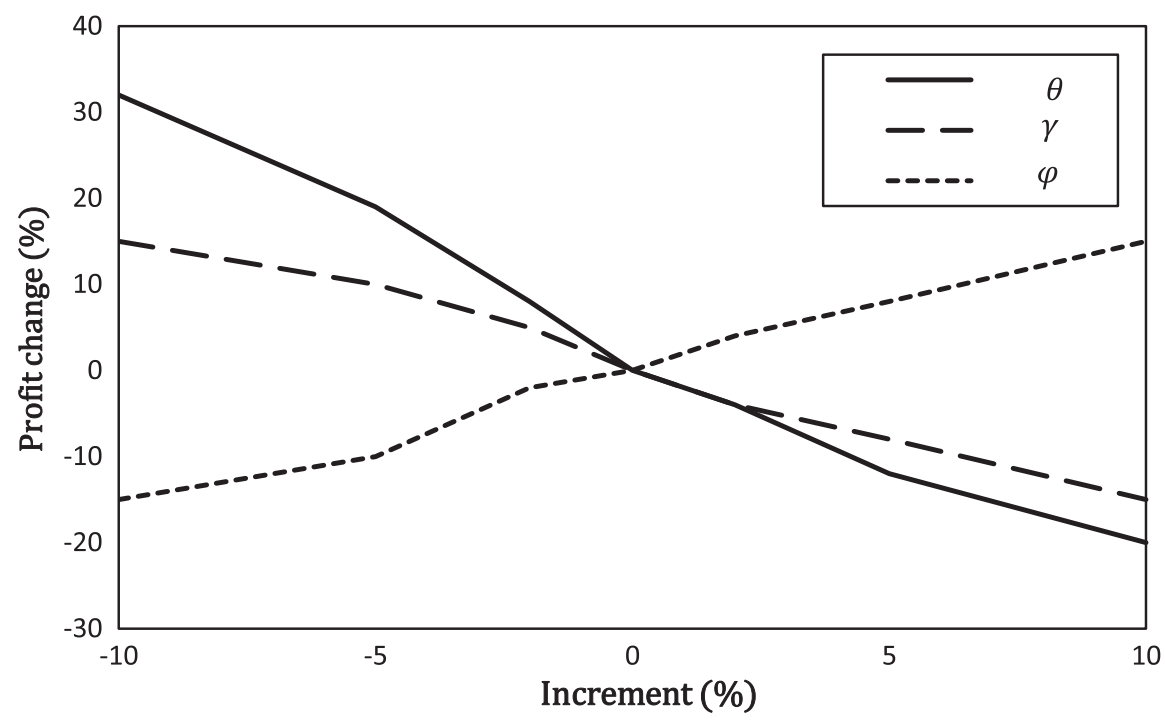

Figure 5. Effects of $\theta, \gamma$, and $\varphi$ changes on the profit of CSC. 


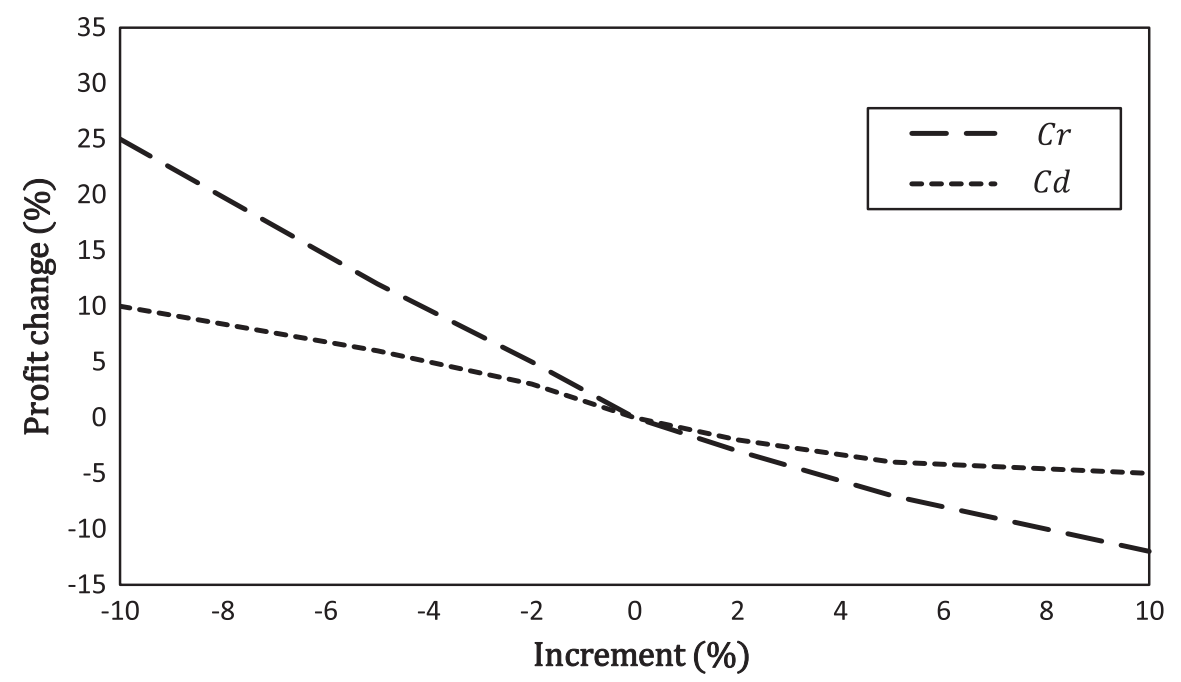

Figure 6. Alteration of $C_{r}$ and $C_{d} v s$. manufacturer's profit function.

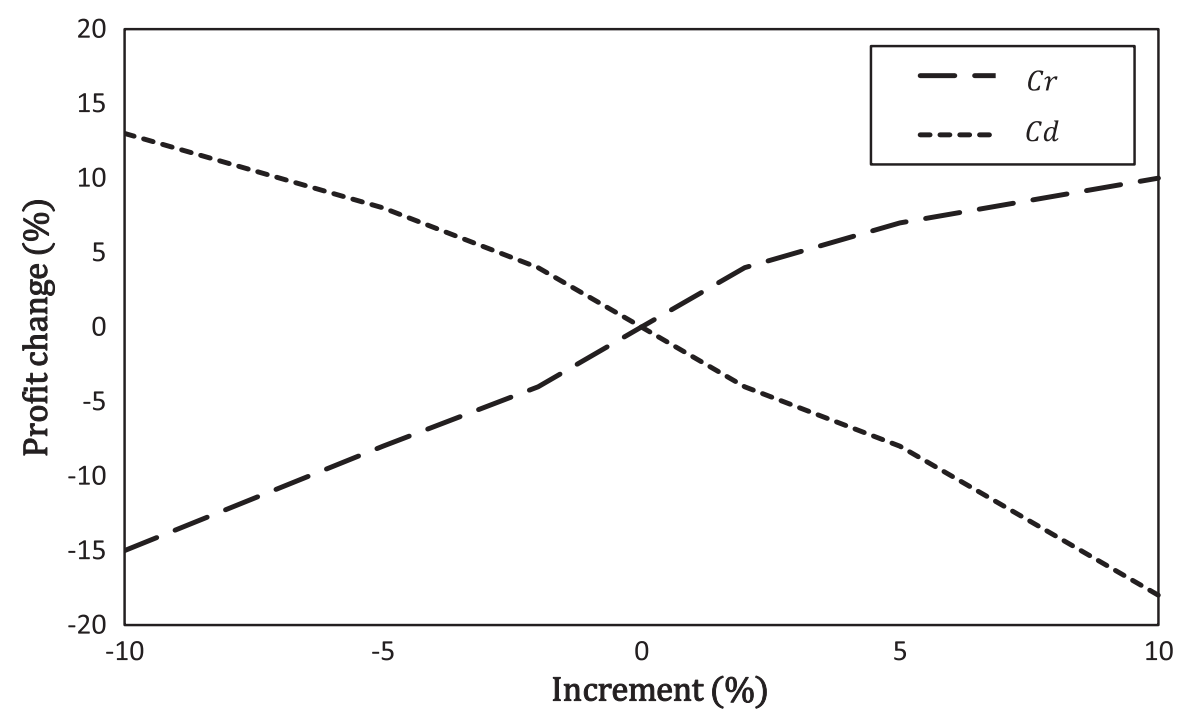

Figure 7. Alteration of $C_{r}$ and $C_{d}$ vs. supplier's profit.

The major insights can be derived by Figure 5 as follows:

- Decision makers should look for ways such as investing in deterioration reduction technology to reduce deterioration rate and keep materials for longer periods.

- Due to the decaying natures of chemical over time, the supplier must look for shorter distances for the transportation of chemicals to provide products with higher quality.

- Coefficient $\gamma$ must be set at an acceptable level from the manufacturer side. In Other words, proper prediction of customer orders cancellation and preparation for the similar incidents causes not to face a sudden increase in administrative costs. 


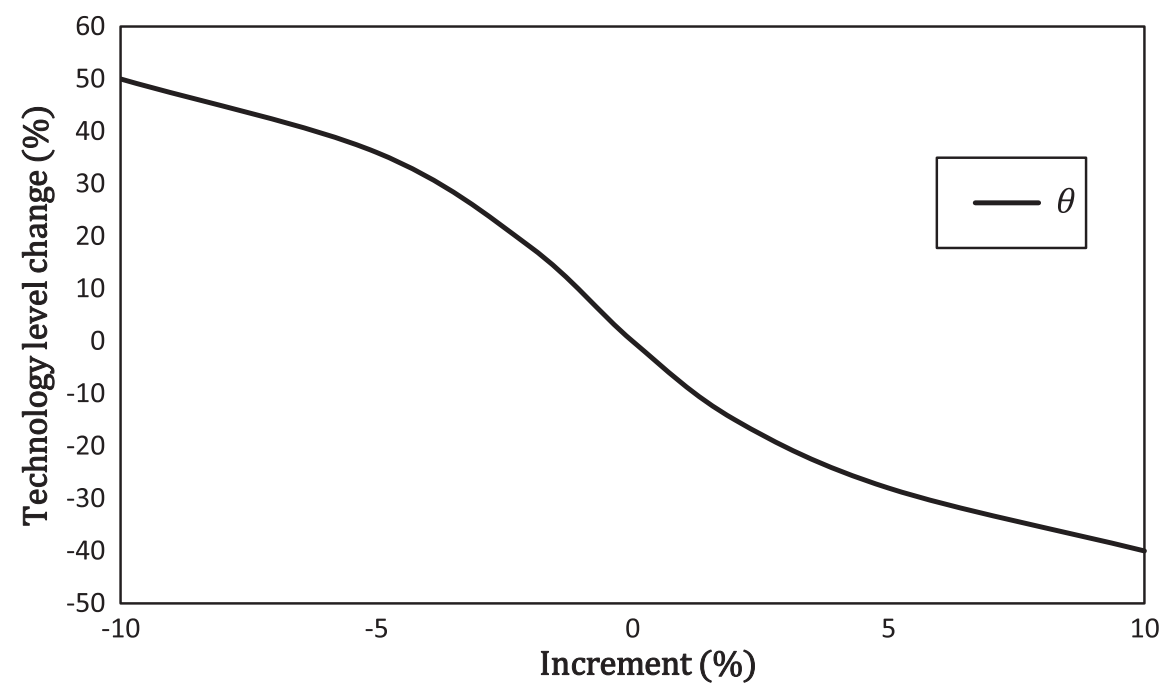

FiguRE 8. Effects of changing in $\theta$ on manufacturer's technology level.

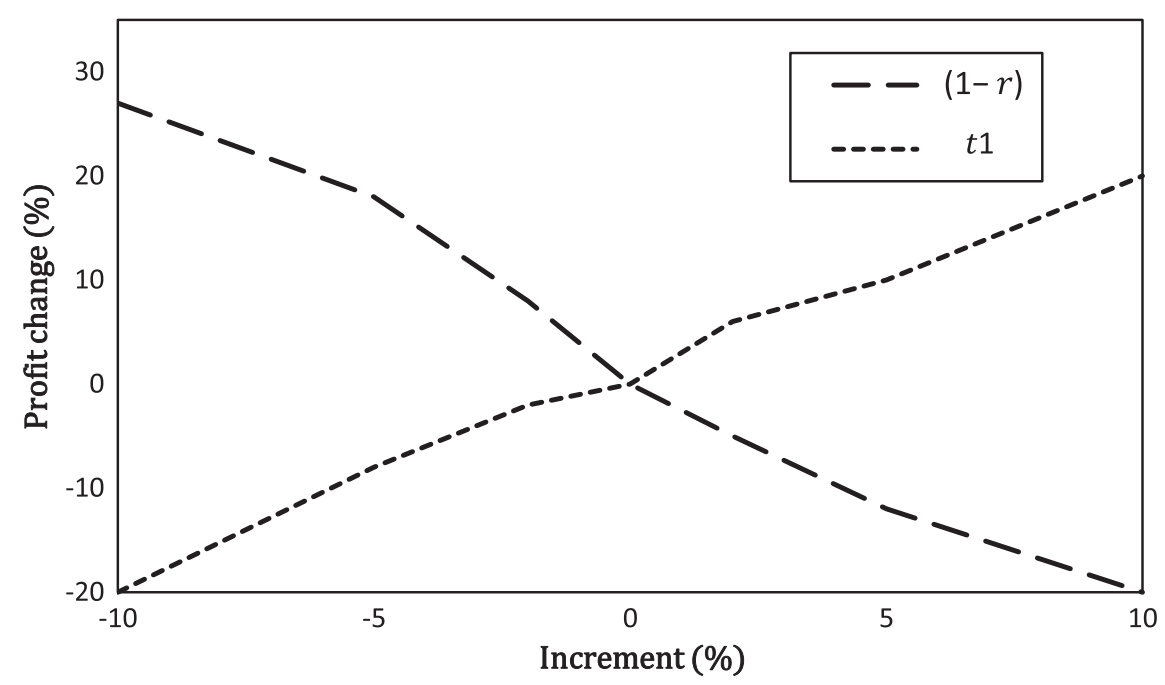

Figure 9. Effects of changing of $(1-r)$ and $t_{1}$ on the CSC profit.

The effects of risk cost and deterioration cost on channel members' profits are also analyzed and the results could be found Figures 6 and 7. As illustrated in Figures 6 and 7, $C_{d}$ has an adverse effect on both members' profit because this cost is imposed on the chain due to the deterioration of the products. By contrast, $C_{r}$ only has a negative effect on the manufacturer's profits and has a positive impact on the supplier's profit. Given the facts (1) the supplier does not use the risk reduction technologies in transportation and storage activities and (2) obtaining a cost-per-transaction agreement for the carriage of hazardous chemicals from the manufacturer, the supplier is more inclined to share more of risk costs with the manufacturer when the received costs increase. On the other hand, this increase in risk costs has a detrimental effect on the manufacturer's profits. 
Some managerial findings can be considered by Figures 6 and 7 as follows:

- CSC's members should minimize the costs of product deterioration through solutions such as timely delivery of products or shortening the shelf life of products in the warehouse.

- The manufacturer must seek to contract with suppliers who use risk reduction technologies in transportation and storage chemicals, in order to pay less risks cost.

- In order to reduce the cost of maintaining these products, both members of the chain should minimize the shelf life time of the products in the warehouse.

The effect of deterioration rate $(\theta)$ on manufacturer's technology level $(g)$ is investigated in Figure 8, which indicates that $\theta$ has a negative effect on manufacturer's technology level. Indeed, as the deterioration rate decreases, the overall profitability of the manufacturer increases so he can invest more in technologies. The main finding of Figure 8 is as follow.

The manufacturer is looking for a way to reduce the deterioration rate in production and maintenance processes. Note that increasing in technology level has a direct correlation with higher demand and higher profits for the manufacturer. Furthermore, the manufacturer can invest in various technologies based on the profits gained on each level of deterioration rate reduction. For example:

- In the range of 5-10 percent increase in the deterioration rate due to a large reduction in profits, the manufacturer can only invest in lower levels of technology and essential risk reduction technologies.

- In a range of 5-10 percent reduction in the deterioration rate, due to the high profitability, the manufacturer can invest in high technology levels and not only implements the best risk reduction technologies but also implements the high levels of quality technology in production process to attract customer satisfaction.

Finally, the effect of $t_{1}$ and $(1-r)$ are investigated in Figure 9. As can be seen in Figure 9, $t_{1}$ has a positive effect and $(1-r)$ has a negative effect on the total profit of CSC. The higher the discount rate offered by the supplier, caused the manufacturer announced his order earlier, and as a result, the profits of both parties and subsequently the total profit of CSC increase. However, by increasing $t_{1}$, the discount factor $(r)$ increases and $(1-r)$ decreases which means that the supplier shares more profit with the manufacturer. As a result of increase in manufacturer's profit, and with reduction in the $(1-r)$, the manufacturer provides a longer deadline for delivering products to the supplier that increases supplier's profit and ultimately increases CSC's profit.

\section{Conclusions}

In recent years, hazardous chemicals have become one of the essential factors for agriculture, the pharmaceutical industry and people daily life. However, the decision-makers of CSC face new challenges because of the high risk of transportation and storage of these materials. On the other hand, since they are in the category of deteriorating items, the quality and quantity gradually decrease over the time. In this study, we considered a two-echelon supply chain with one supplier and one manufacturer with constant deterioration rate in which the market demand is sensitive to technology level and lead-time The manufacturer invests in the risk reduction technology and quality improvement technology to reduce risks and increase product's quality. In order to coordinate the CSC, a lead-time based discount contract with the aim of increasing the CSC profit is presented. The supplier proposes such a lead-time based contract to encourage the manufacturer to order earlier. By doing so, the supplier provides high-quality products and the manufacturer's unit supplying cost reduces and can buy more chemicals from the supplier; hence, the profit of manufacturer increases simultaneously. On the other hand, the supplier will have more time to supply the product and its initial cost will be reduced. As a result, the supplier's profit will also increase.

Further studies could analyze the situation for a supply chain with more than one supplier or retailer or even both. In addition, both sides investigate on risk reduction technology and quality improvement technology. Also, in order to make the more realistic perspectives, it is possible to consider several products or even seasonal products. Another direction is considering the behavior of deteriorating products in reality, the deterioration 
rate may not be considered a constant rate throughout the entire period of time and should be used as a time variable.

\section{Appendix A. Proof of Theorem 4.1}

The order quantity of the manufacturer can be given by

$$
Q=I_{m}(0)=\frac{\left(a+b l t_{m}+s g\right)}{\theta}\left[e^{\theta T}-1\right]
$$

and

$$
I_{m}=\int_{0}^{T} I_{m}(t) \mathrm{d} t=\frac{\left(-1+e^{\theta T}-\theta T\right)\left(a+b l t_{m}+s g\right)}{\theta^{2}} .
$$

As a result, according to equations (4.5) and (4.6), the quantity of the product sold by the manufacturer is as equation (4.4).

\section{Appendix B. Proof of Theorem 4.2}

Since the first principal minor is negative $-2 \gamma<0$ and the second principal minor is positive $2 \gamma \eta>0$, the manufacturer's expected profit function is concave in both $l t_{m}$ and $g$. Hence, the optimal solution can be obtained if the corresponding parameters satisfy the conditions mentioned for concavity.

$$
\begin{aligned}
& H=\left[\begin{array}{ll}
\frac{\partial^{2} \Pi_{m}}{\partial l t_{m}^{2}} & \frac{\partial \Pi_{m}}{\partial l t_{m} \partial g} \\
\frac{\partial \Pi_{m}}{\partial g \partial l t_{m}} & \frac{\partial \Pi_{m}}{\partial g^{2}}
\end{array}\right] \\
& H=\left[\begin{array}{ll}
-2 \gamma & 0 \\
0 & -\eta
\end{array}\right] .
\end{aligned}
$$

\section{Appendix C. Proof of Theorem 4.3}

Equation (4.9) should be equal to $Q$ at $T$. Hence, this equation can be rewritten as follows:

$$
\begin{gathered}
I_{s}(t)=\frac{q}{\theta}\left[1-e^{\theta\left(\left(T-l t_{s}\right)-t\right)}\right] \\
\frac{q}{\theta}\left[1-e^{\theta\left(\left(T-l t_{s}\right)-T\right)}\right]=Q .
\end{gathered}
$$

Respectively, equation (4.9) should be equal to 0 at $T-l t$; hence, equation (4.9) is rewritten as follows:

$$
\frac{q}{\theta}\left[1-e^{\theta\left(\left(T-l t_{s}\right)-t\left(t-l t_{s}\right)\right)}\right]=0 .
$$

Concluding from equations (C.2) and (C.3), we have:

$$
\begin{aligned}
q & =\frac{Q \theta}{1-e^{-\theta l t_{s}}} \\
I_{s}(t) & =\frac{Q}{1-e^{-\theta l t_{s}}}\left[1-e^{\theta\left(\left(T-l t_{s}\right)-t\right)}\right] \\
\int_{T-l t_{s}}^{T} I_{s}(t) \mathrm{d} t & =I_{s}=Q\left(\frac{l t_{s}}{1-e^{-\theta l t_{s}}}-\frac{1}{\theta}\right) .
\end{aligned}
$$




\section{REFERENCES}

[1] A. Adhitya and R. Srinivasan, Dynamic simulation and decision support for multisite specialty chemicals supply chain. Ind. Eng. Chem. Res. 49 (2010) 9917-9931.

[2] J. Asl-Najafi and S. Yaghoubi, A novel perspective on closed-loop supply chain coordination: product life-cycle approach. J. Cleaner Prod. 289 (2021) 125697.

[3] J. Asl-Najafi, B. Zahiri, A. Bozorgi-Amiri and A. Taheri-Moghaddam, A dynamic closed-loop location-inventory problem under disruption risk. Comput. Ind. Eng. 90 (2015) 414-428.

[4] Q.G. Bai, X.H. Xu, M.Y. Chen and Q. Luo, A two-echelon supply chain coordination for deteriorating item with a multi-variable continuous demand function. Int. J. Syst. Sci.: Oper. Logistics 2 (2015) 49-62.

[5] Q. Bai, M. Chen and L. Xu, Revenue and promotional cost-sharing contract versus two-part tariff contract in coordinating sustainable supply chain systems with deteriorating items. Int. J. Prod. Econ. 187 (2017) 85-101.

[6] Q. Bai, M. Jin and X. Xu, Effects of carbon emission reduction on supply chain coordination with vendor-managed deteriorating product inventory. Int. J. Prod. Econ. 208 (2019) 83-99.

[7] R. Bubbico, S. Di Cave and B. Mazzarotta, Risk analysis for road and rail transport of hazardous materials: a simplified approach. J. Loss Prev. Process Ind. 17 (2004) 477-482.

[8] G.P. Cachon, Supply chain coordination with contracts. Handbooks Oper. Res. Manage. Sci. 11 (2003) 227-339.

[9] D. Chakraborty, D.K. Jana and T.K. Roy, Multi-item integrated supply chain model for deteriorating items with stock dependent demand under fuzzy random and bifuzzy environments. Comput. Ind. Eng. 88 (2015) 166-180.

[10] H.C. Chang, An analysis of production-inventory models with deteriorating items in a two-echelon supply chain. Appl. Math. Model. 38 (2014) 1187-1191.

[11] Y. Daryanto, H.M. Wee and G.A. Widyadana, Low carbon supply chain coordination for imperfect quality deteriorating items. Mathematics 7 (2019) 234.

[12] E. Erkut and V. Verter, Modeling of transport risk for hazardous materials. Oper. Res. 46 (1998) 625-642.

[13] European Commission, Council Directive 82/501/EEC of 24 June 1982 on the major-accident hazards of certain industrial activities. Official J. Eur. Communities L230 (1982) 1-18.

[14] European Commission, Council Directive 96/82/EC of 9 December 1996 on the control of major-accident hazards involving dangerous substances. Official J. Eur. Communities L10 (1997) 13.

[15] European Commission, Directive 2003/105/EC of the European Parliament and of the Council of 16 December 2003 amending Council Directive 96/82/EC on the control of major-accident hazards involving dangerous substances. Official J. Eur. Communities L345 (2003) 97-105.

[16] European Commission, European Parliament and Council Directive 2012/18/ EU of 4 July 2012 on control of major-accident hazards involving dangerous substances amending and subsequently repealing council directive 96/82/EC. Official J. Eur. Communities L197 (2012) 1-37.

[17] B. Fabiano, F. Currò, A.P. Reverberi and R. Pastorino, Dangerous good transportation by road: from risk analysis to emergency planning. J. Loss Prev. Process Ind. 18 (2005) 403-413.

[18] M.E. Ferguson and O. Koenigsberg, How should a firm manage deteriorating inventory? Prod. Oper. Manage. 16 (2007) $306-321$.

[19] Y. Gao, Z. Shang and A. Kokossis, Agent-based intelligent system development for decision support in chemical process industry. Expert Syst. App. 36 (2009) 11099-11107.

[20] P. Gautam and A. Khanna, An imperfect production inventory model with setup cost reduction and carbon emission for an integrated supply chain. Uncertain Supply Chain Manage. 6 (2018) 271-286.

[21] P. Gautam, A. Kishore, A. Khanna and C.K. Jaggi, Strategic defect management for a sustainable green supply chain. J. Cleaner Prod. 233 (2019) 226-241.

[22] Y. Ghiami, T. Williams and Y. Wu, A two-echelon inventory model for a deteriorating item with stock-dependent demand partial backlogging and capacity constraints. Eur. J. Oper. Res. 231 (2013) 587-597.

[23] B.C. Giri and T. Maiti, Supply chain model for a deteriorating product with time-varying demand and production rate. $J$. Oper. Res. Soc. 63 (2012) 665-673.

[24] X. Guo and M. Verma, Choosing vehicle capacity to minimize risk for transporting flammable materials. J. Loss Prev. Process Ind. 23 (2010) 220-225.

[25] Y. He, S.Y. Wang and K.K. Lai, An optimal production-inventory model for deteriorating items with multiple-market demand. Eur. J. Oper. Res. 203 (2010) 593-600.

[26] J. Heydari, Lead time variation control using reliable shipment equipment: an incentive scheme for supply chain coordination. Transp. Res. Part E: Logistics Transp. Rev. 63 (2014) 44-58.

[27] J. Heydari and J. Asl-Najafi, Coordinating inventory decisions in a two-echelon supply chain through the target sales rebate contract. Int. J. Inventory Res. 3 (2016) 49-69.

[28] J. Heydari and J. Asl-Najafi, A revised sales rebate contract with effort-dependent demand: a channel coordination approach. Int. Trans. Oper. Res. 28 (2021) 438-469.

[29] M.A. Hoque, An optimal solution technique to the single-vendor multi-buyer integrated inventory supply chain by incorporating some realistic factors. Eur. J. Oper. Res. 215 (2011) 80-88.

[30] P.H. Hsu, H.M. Wee and H.M. Teng, Preservation technology investment for deteriorating inventory. Int. J. Prod. Econ. 124 (2010) 388-394. 
[31] Y.S. Huang, W.J. Su and Z.L. Lin, A study on lead-time discount coordination for deteriorating products. Eur. J. Oper. Res. 215 (2011) 358-366.

[32] H. Huang, Y. He and D. Li, Pricing and inventory decisions in the food supply chain with production disruption and controllable deterioration. J. Cleaner Prod. 180 (2018) 280-296.

[33] I.A. Karimi, R. Srinivasan and P.L. Han, Unlock supply chain improvements through effective logistics. Chem. Eng. Prog. 98 (2002) 32-38

[34] A. Khanna, P. Gautam, B. Sarkar and C.K. Jaggi, Integrated vendor-buyer strategies for imperfect production systems with maintenance and warranty policy. RAIRO:OR 54 (2020) 435-450.

[35] P.R. Kleindorfer and G.H. Saad, Managing disruption risks in supply chains. Prod. Oper. Manage. 14 (2005) 53-68.

[36] J.M. Laínez and L. Puigjaner, Prospective and perspective review in integrated supply chain modelling for the chemical process industry. Curr. Opin. Chem. Eng. 1 (2012) 430-445.

[37] Y. Li, X. Xu and F. Ye, Supply chain coordination model with controllable lead time and service level constraint. Comput. Ind. Eng. 61 (2011) 858-864.

[38] C. Li, J. Ren and H. Wang, A system dynamics simulation model of chemical supply chain transportation risk management systems. Comput. Chem. Eng. 89 (2016) 71-83.

[39] G.C. Lin, D.E. Kroll and C.J. Lin, Determining a common production cycle time for an economic lot scheduling problem with deteriorating items. Eur. J. Oper. Res. 173 (2006) 669-682.

[40] X. Ma, J. Wang, Q. Bai and S. Wang, Optimization of a three-echelon cold chain considering freshness-keeping efforts under cap-and-trade regulation in Industry 4.0. Int. J. Prod. Econ. 220 (2020) 107457.

[41] M. Malekitabar, S. Yaghoubi and M.R. Gholamian, A novel mathematical inventory model for growing-mortal items (case study: Rainbow trout). Appl. Math. Model. 71 (2019) 96-117.

[42] K.F. Matta, Ordering policies for the cyclical replenishment problem given leadtime-dependent discounts. Eur. J. Oper. Res. 73 (1994) 465-471.

[43] S. Nahmias, Perishable inventory theory: a review. Oper. Res. 30 (1982) 680-708.

[44] M. Rahdar and A.S, Nookabadi, Coordination mechanism for a deteriorating item in a two-level supply chain system. Appl. Math. Modell. 38 (2014) 2884-2900.

[45] D. Sirias and S. Mehra, Quantity discount versus lead time-dependent discount in an inter-organizational supply chain. Int. J. Prod. Res. 43 (2005) 3481-3496.

[46] S. Tiwari, C.K. Jaggi, M. Gupta and L.E. Cárdenas-Barrón, Optimal pricing and lot-sizing policy for supply chain system with deteriorating items under limited storage capacity. Int. J. Prod. Econ. 200 (2018) 278-290.

[47] S. Tiwari, Y. Daryanto and H.M. Wee, Sustainable inventory management with deteriorating and imperfect quality items considering carbon emission. J. Cleaner Prod. 192 (2018) 281-292.

[48] G. Wei, Z.F. Yang and Y.H. Li, A statistic analysis and countermeasures on non-explosive dangerous chemial accidents in recent 3 years. Journal of Beijing Normal University (Natural Science) 41 (2005) 209-212.

[49] H. Wei, J. Li and H. Wang, Analysis of total risk of hazardous materials during transportation. Chin. Saf. Sci. J. 15 (2005) $97-101$.

[50] Z.Z. Wu and M. Sun, Statistic analysis and countermeasure study on 200 road transportation accidents of dangerous chemicals. J. Safety Sci. Technol. 2 (2006) 3-8.

[51] T. Xiao and T. Xu, Coordinating price and service level decisions for a supply chain with deteriorating item under vendor managed inventory. Int. J. Prod. Econ. 145 (2013) 743-752.

[52] C. Yan, A. Banerjee and L. Yang, An integrated production-distribution model for a deteriorating inventory item. Int. J. Prod. Econ. 133 (2011) 228-232.

[53] P.C. Yang and H.M. Wee, A single-vendor and multiple-buyers production-inventory policy for a deteriorating item. Eur. J. Oper. Res. 143 (2002) 570-581.

[54] J. Zhang, G. Liu, Q. Zhang and Z. Bai, Coordinating a supply chain for deteriorating items with a revenue sharing and cooperative investment contract. Omega 56 (2015) 37-49.

[55] P.C. Yang and H.M. Wee, An integrated multi-lot-size production inventory model for deteriorating item. Comput. Oper. Res. 30 (2003) 671-682.

[56] J.H. Zhang and L.J. Zhao, Risk analysis of dangerous chemicals transportation. Syst. Eng.-Theory Pract. 27 (2007) 117-122.

[57] J. Zhang, J. Hodgson and E. Erkut, Using GIS to assess the risks of hazardous materials transport in networks. European Journal of Operational Research 121 (2000) 316-329.

[58] www. payamch.com.

[59] www.mbkchemical.com. 